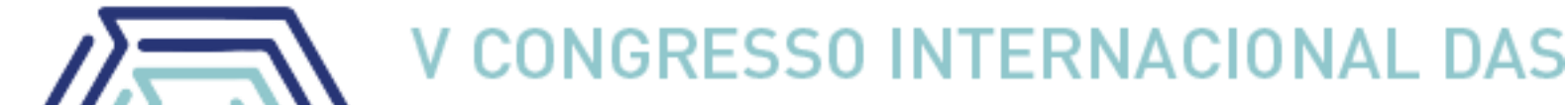 LICENCIATURAS COINTER - PDVL 2018
}

\section{O ENSINO DE QUÍMICA E PRÁTICAS DE DESENVOLVIMENTO SUSTENTÁVEL EM ESPAÇO NÃO FORMAL DE APRENDIZAGEM E PRESENÇA DA INTERDISCIPLINARIDADE NO ENGENHO SANHAÇU - PE}

\section{THE TEACHING OF CHEMISTRY AND SUSTAINABLE DEVELOPMENT PRACTICES IN NON-FORMAL SPACE OF LEARNING AND PRESENCE OF INTERDISCIPLINARITY IN SANHAÇU ENGINEERING - PE}

\author{
Apresentação: Relato de Experiência \\ Fernanda Karoline da Silva ${ }^{1}$; Stefanie Ingrid Tavares Ribeiro ${ }^{2}$; Fabiola Lemos ${ }^{3}$ \\ DOI: https://doi.org/10.31692/2358-9728.VCOINTERPDVL.2018.00294
}

\section{Introdução}

Atualmente é cada vez mais difícil entreter os alunos na educação das ciências da natureza, como por exemplo a química, logo este relato de experiência busca explanar o ensino da química em um espaço não formal de aprendizagem com a presença da interdisciplinaridade, mostrando a experiência vivenciada pelo Programa de Extensão no Engenho Sanhaçu, na aprendizagem da química com o envolvimento de um ambiente com desenvolvimento de causas sustentáveis.

\section{Relato de Experiência}

De acordo com os Parâmetros Curriculares Nacionais para o Ensino Médio - PCNEM (BRASIL, 2002) os conteúdos abordados no ensino de Química não devem se resumir à mera transmissão de informações, definições e leis isoladas que não possuem qualquer relação com o cotidiano do alunado, seus interesses e suas vivências, exige-se quase sempre a pura memorização dos conteúdos, impossibilitando uma aprendizagem significativa. Desta forma, o relato busca identificar práticas sustentáveis com concomitância ao ensino de química ambiental em um espaço não formal de aprendizagem, auxiliando no desenvolvimento humano e na educação interdisciplinar.

\footnotetext{
${ }^{1}$ Licenciatura em Química, Instituto Federal de Pernambuco - IFPE, fernandakds@hotmail.com

${ }^{2}$ Licenciatura em Química, Instituto Federal de Pernambuco - IFPE, stefanieingrid@hotmail.com

${ }^{3}$ Mestre, Instituto Federal de Pernambuco - IFPE, fabiola.lemos@vitoria.ifpe.edu.br
} 
O estudo teve caráter qualitativo descritivo, fundamentando-se na observação direta intensiva, que se baseia na técnica de coletar dados e em examinar fatos ou fenômenos estudados, tendo por modalidade a observação não estruturada, assistemática, através de uma experiência casual, de participação individual efetuada na vida real, (MARCONI E LAKATOS, 2010).

Deste modo, realizou-se uma visita acadêmica para o Engenho Sanhaçu, localizado no município de Chã Grande, estado de Pernambuco, durante o turno da manhã e estendeu-se até a o início da tarde. Ao chagar no espaço da visita pedagógica acadêmica uma representante turística do local mostrou as áreas envolvidas no processo diário e uso dos recursos do engenho. No primeiro momento foi feita uma apresentação geral do local, como por exemplo, de onde surgiu a ideia de ter uma cachaçaria orgânica, a origem do engenho que estão localizados, exposição geral das atividades feitas, entre outros. A exposição da apresentação foi feita em ambiente propício para visitantes, sendo este favorável. Em um segundo momento a guia encaminhou para a área onde é feito os processos da preparação da cachaça e produtos derivados da cana de açúcar.

Tendo em vista a formação de docente, é notório que a visita colaborou em diversas áreas da aprendizagem dos conteúdos expostos em aulas no local de ensino formal. Foram abordados na visita assuntos relacionados a química como, processo de diluição, fermentação, destilação, energia renováveis, gravidade e demais temas envolvidos, fatores que colaboram para a aprendizagem interdisciplinar dos discentes, auxiliando no seu desenvolvimento e formação pessoal.

Além dos conteúdos diretamente relacionamos a química, foi possível observar também que a visita estabeleceu temas das diversas áreas da aprendizagem pessoal e curricular. Sendo a mesma, de grande prestígio para a aprendizagem descontraída, interdisciplinar e dinâmica de diversos temas e processo de socialização com o meio não só pessoal, como também ecológico e sustentável, pois por ser um ambiente rural é de essencial importância a preservação, cuidado e manejo apropriado do espaço, como os aspectos sustentáveis e conhecimento do não desmatamento, poluição, descarte adequado e usos renováveis de energia. Sendo este último um recuso sustentável explorado no engenho a partir da energia solar e eólica.

Na pratica orgânica, presente da preparação na cachaça feita no engenho, não é utilizado quaisquer químicas para a preservação de pragas na plantação, por exemplos, os processos 
orgânicos são feitos de maneira sustentável, visando o bem-estar e o mínimo impacto ambiental, diferente da pratica agroindustrial, que faz uso de produtos químicos na preservação de pragas.

Em suma, a área proporciona a possibilidade de se trabalhar temas interdisciplinares e científicos em espaços não formais, sendo de grande importância para obter uma visão mais ampla sobre a educação que pode desenvolver o caráter de sensibilizador e científico, envolvendo à aprendizagem significativa e mais coletiva.

A imagem abaixo mostra o espaço que os visitantes foram recebidos pela representante turística do Engenho Sanhaçu, o preparo dos cubos doces a partir da cana de açúcar, pois a empresa além de fabricar a cachaça também recupera o açúcar da cana de açúcar para que nada seja descartado reaproveitando quase tudo no processo de produção da cachaça e por fim, o armazenamento da cachaça nos toneis de freijó, carvalho e umburana para proporcionar características especiais, aroma e sabor.

Imagem 1: Engenho Sanhaçu. Fonte: Própria
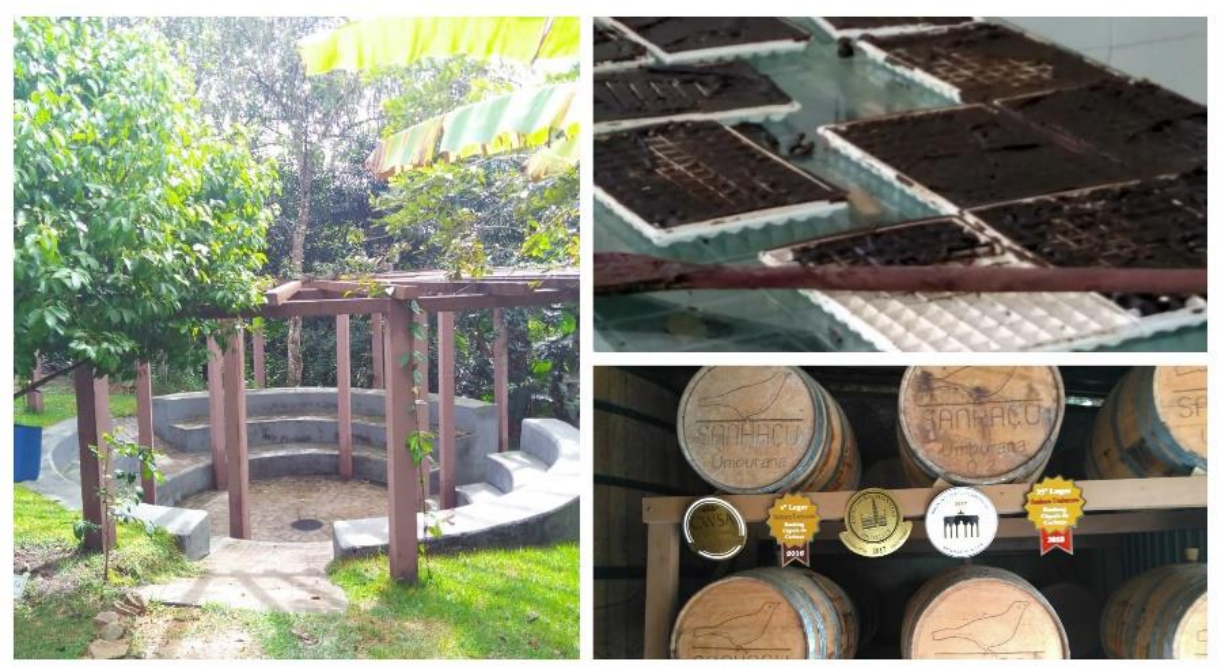

\section{Considerações}

A forma com que a empresa recebeu os visitantes colaboram para que a experiência de extensão vivenciada atingisse um bom desempenho e prestígio , estabelecendo contribuições significativas para o desenvolvimento da visita acadêmica pedagógica em um espeço não formal de aprendizagem com aspecto interdisciplinar relacionado temas das diversas áreas de conhecimento como, química, física e biologia, presente da preparação da cachaça, energias renováveis e não desmatamento, respectivamente, além de contribuir para o ensino e aprendizagem da educação ambiental e química verde, abordando a consciência do descarte adequado de resíduos líquidos e sólidos. Sendo assim, os conteúdos de aprendizagem da visita 
pedagógica acadêmica partiram de temas que permitiu a contextualização e a relação entre diferentes áreas do conhecimento sendo de grande importância para o processo de desenvolvimento e aprendizagem do aluno, além de usufruir da socialização escolar.

\section{Referências}

BRASIL, MEC. As Novas Diretrizes Curriculares que mudam o Ensino Médio Brasileiro, Brasília, 2002.

MARCONI, Marina de Andrade; LAKATOS, Eva Maria. Fundamentos de metodologia científica. 7. ed. São Paulo: Atlas, 2010. 